\section{Edyrcasaio

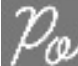

DossIÊ

\section{Editora}

Maria Inês Côrte Vitoria

PUCRS, RS, Brasil

\section{Editora Colaboradora}

Pricila Kohls dos Santos

PUCRS, RS, Brasil

\section{Equipe Editorial}

Carla Spagnolo

PUCRS, Brasil

Rosa Maria Rigo

PUCRS, Brasil

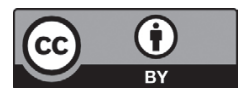

Este artigo está licenciado sob forma de uma licença Creative Commons Atribuição 4.0 Internacional, que permite uso irrestrito, distribuiçăo e reproduçáo seja corretamente citada. http://creativecommons.org/licenses/by/4.0/deed.pt BP

\title{
Formação docente e protagonismo estudantil de acadêmicos de Medicina: desafios e perspectivas
}

\author{
Teacher training and student protagonism of Medical students:
} challenges and perspectives

\author{
Adan Renê Pereira da Silva \\ Anne Karina Pereira de Andrade ${ }^{2}$ \\ Nilza Oliveira dos Santos ${ }^{3}$
}

\section{RESUMO}

A docência no campo médico tem se constituído em desafio para a formação e exigido a reflexão em torno de perspectivas. O objetivo é discutir alguns desses desafios apontados pela literatura, privilegiando o protagonismo estudantil. Para isso, empreendeu-se pesquisa de revisão bibliográfica, focando autores que tratam da temática. Os resultados mostraram que a formação inicial e continuada de professores na área é urgente, principalmente quando se considera a ausência dela, a falta de percepção do aluno como sujeito da aprendizagem e silenciamentos de questões que potencializam a evasão escolar discente, como excesso de cobrança e pouco protagonismo estudantil. Concluiu-se que, por ser o campo da formação de professores incipiente, necessita ser revisitado: o professormédico precisa se perceber mais professor, o que o levará a pensar o campo pedagógico, e menos médico, para relativizar paradigmas de sua própria formação e enxergar o aluno em uma perspectiva biopsicossocial, mais como sujeito e menos como paciente.

Palavras-chave: Formação docente; Protagonismo estudantil; Formação médica.

\section{ABTRACT}

Teaching in the medical field has become a challenge for training and requires reflection on perspectives. The objective is to discuss some of these challenges pointed out in the literature, favoring student protagonism. For this, we undertook research of bibliographic revision, focusing on authors that deal with the theme. The

\footnotetext{
${ }^{1}$ Doutorando em Educação pela Universidade Federal do Amazonas, Mestre em Psicologia, Especialista em História da Saúde na Amazônia. Psicólogo.

2 Mestre em Saúde Pública, Faculdade de Medicina da Universidade Federal do Amazonas

${ }^{3}$ Graduada em Serviço Social, Faculdade de Medicina da Universidade Federal do Amazonas.
} 
results showed that initial and continuing teacher training in the area is urgent, especially when one considers the absence of the teacher, the student's lack of perception as a subject of learning and the silencing of issues that increase student dropout, such as excessive collection and little student protagonism. It was concluded that, because it is the field of incipient teacher training, it needs to be revisited: the teacher-doctor needs to perceive more teacher, which will lead him to think of the pedagogical field, and less medical, to relativize paradigms of his own formation and to see the student in a biopsychosocial perspective, more as a subject and less as a patient.

Keywords: Teacher training; Student leadership; Medical training.

\section{Introdução}

667 ornar-se médico" pode ser pensado como um processo longo e dispendioso. Há farto material na literatura

1 científica que elenca aspectos singulares da formação médica (MILAN et al., 1999; BELLODI, 2005; MELEIRO, 2005; MEDEIROS; ALMEIDA; RIBEIRO, 2012, entre outros). Da ideia de vocação, passando pela criação de uma identidade profissional e desembocando no sofrimento psíquico durante o curso, o estudante figura em um dos polos como interlocutor de um caminho atravessado por diversos atores: professores, pacientes, colegas, a escola médica, ambiente hospitalar, vida pessoal, entre outros. Protagônico nesse caminhar está a relação professoraluno, incluindo a formação do docente e o quanto o aluno é agente ou "paciente" no desenrolar dos anos em que "aprende" a ser médico. Entende-se protagonismo estudantil, nesse trabalho, como os processos que centralizam a atenção no aluno, dando vez e voz a esses sujeitos, por entender que eles são os principais interessados em aprender.

Os autores do artigo encontram-se imiscuídos nesse debate. De um lado, atuando em um Núcleo de Apoio de uma escola médica. De outro, pesquisando a formação docente e como o acadêmico desenvolve-se na graduação. Assim, torna-se relevante estar em constante processo de estudo, ajudando a produzir reflexões sobre o tema, trabalhando vulnerabilidades e fortalecendo potências.

Acadêmicos de Medicina figuram constantemente como alvo de preocupação. A própria função social do médico ajuda a entender a razão disso. Em 2017, por exemplo, pôde-se acompanhar matéria do Senado (disponível em: $<$ https://www 12.senado.leg.br/noticias/materias/2017/11/30/projeto-preve-assistencia-psiquiatrica-e-psicologicapara-estudantes-de-medicina $>$ ), com um projeto de lei para estudantes de Medicina. O texto expõe que: “[...] o projeto tem o objetivo de assegurar a assistência emocional e psicológica para esses estudantes que [...] desde o processo de seleção para ingresso na faculdade, passam por altos níveis de estresse”. 
Para comprovar seu argumento, a propositora aponta o alto grau de responsabilidade, bem como aspectos emocionais que circundam a vida acadêmica de discentes (estresse, ansiedade, depressão), por meio de um estudo com 1.350 estudantes de Medicina, de variadas escolas médicas brasileiras. O estudo é de Fernanda Mayer, da Universidade de São Paulo, que revelou significativa presença de sintomas depressivos e ansiedade, além de cansaço, irritabilidade e distúrbio do sono, entre discentes.

Ainda de acordo com a fonte:

A saúde mental de estudantes de cursos de Medicina voltou a ser um ponto de preocupação recentemente. No dia 28 de novembro, foi divulgado pela imprensa o segundo caso em dez dias de suicídio entre estudantes de Medicina da Faculdade de Minas (Faminas), de Belo Horizonte. Em maio deste ano, casos de suicídio na Universidade Federal de Minas Gerais (UFMG) também chamaram a atenção pelo curto espaço de tempo entre as ocorrências.

Assim, pretende-se aqui discorrer sobre desafios e perspectivas para a formação do médico docente, no intuito de privilegiar a ascensão de um protagonismo estudantil, por entender-se que tal protagonismo tende a pensar o estudante como sujeito e não como mero espectador. Pensa-se a importância de contribuir para a discussão sobre as especificidades da formação médica, já que os alunos de hoje serão os médicos que amanhã cuidarão da saúde da população. Nesse sentido, importante desenvolver profissionais que saibam cuidar da sociedade, cuidado aprendido também ao recebê-lo, o que, por um lado, é responsabilidade da escola médica, por outro, pelo desenvolvimento do autocuidado. Afinal, como afirma Arruda (2005), quem tem por ocupação curar, torna-se obrigado a se cuidar.

Entendeu-se que a melhor forma de realizar o proposto seria por meio de uma pesquisa bibliográfica, por permitir verificar dados que mostrem desafios e perspectivas, neste caso, para a formação de professores no campo médico e sua relação com o protagonismo estudantil. Esta opção permitiu traçar-se um panorama de como tais questões estão sendo construídas no campo da formação docente e quais são as implicações desse percurso para o cenário contemporâneo da escola médica. Além disso, também se deu, entre outros motivos, pela concordância de que os estudos que têm por finalidade a realização de revisão bibliográfica permitem a compreensão do movimento da área, sua configuração, propensões teórico-metodológicas e análise crítica, indicando tendências, recorrências e lacunas (VOSGERAU; ROMANOWSKI, 2014).

Procurou-se utilizar autores referendados pela literatura como relevantes na abordagem da temática, o que foi efetivado mediante a seleção de leituras planejadas, as quais serviram para identificar as diferentes contribuições científicas para permitir o alcance do objetivo proposto. 
Os textos pesquisados abrangeram principalmente livros, artigos indexados em sites acadêmicos e demais produções técnicas validadas no meio científico. Dessa forma, as informações puderam ser cruzadas e checadas, o que enriqueceu sobremaneira o trabalho de pesquisa.

O problema que norteou o desenvolvimento da pesquisa foi: Como a formação de professores, no campo médico, estimula ou desestimula o protagonismo discente e quais são os desafios e perspectivas nesse campo?

Daí a opção pelo objetivo de discutir perspectivas e desafios da formação médica com foco na imbricação da relação professor-aluno.

\section{A formação médica e o aluno em perspectiva: primeiros desafios}

A escola médica vem sendo apontada pela literatura como local de sofrimento psíquico. Entende-se que tal constatação ajuda a pensar desafios para uma formação em que o discente perceba-se protagonista. Nessa primeira parte, decidiu-se analisar alguns pontos do cenário dessa relação entre aluno e local de formação, apresentando ao leitor o estudante do curso de Medicina e como aparece descrito em parte da literatura sobre o tema.

Já em estudo de 20 anos atrás, Meleiro (1998) mostrava a elevada taxa de suicídio entre médicos, apontando, entre as principais causas, o fato de que esse profissional tende a negar o estresse, negar o desconforto psicológico, acobertar tendências suicidas - tornando o tratamento mais difícil -, fechar-se em esquemas defensivos - o que impediria intervenção terapêutica -, ter mais negligência da família e dos colegas - afinal, se é médico, sabe se cuidar -, e, por fim, médicos têm maior facilidade em obter métodos suicidas eficazes.

Muitas das questões que potencializam tal fato começam na graduação. A autora, nesse mesmo estudo, revisa produção científica de 1968, a qual mostra que, desde aquela época, alunos de medicina com melhor desempenho, em 62 escolas médicas norte-americanas e 3 canadenses, apresentavam maiores probabilidades de suicídio. O suicídio foi apontado como a segunda causa de morte entre os estudantes, perdendo apenas para os acidentes. Quando replicado na Faculdade de Medicina da USP, as pesquisas aproximaram-se do resultado nesse universo internacional. Conclui a autora (1998, p. 138):

[...] O estudante passa a ter culpa pelo que não sabe e com isso se sente paralisado pelo medo de errar. Esses quadros caracterizam-se por sentimentos de desvalia e impotência, que, muitas vezes, são responsáveis por ideias de abandono do curso, depressão e suicídio. 
Interessante como os futuros pares e outros médicos que acolhem médicos nessa situação tendem a vê-la (1998, p. 139):

A equipe médica que trata de um paciente médico que tentou suicídio sente-se, geralmente, muito mobilizada e, por vezes, impotente. Quando a tentativa de suicídio envolve um estudante de medicina, algumas vezes, a equipe o hostiliza, considerando-o como fraco. De outro lado, isso sensibiliza muito seus colegas de turma, que se mostram chocados e preocupados com a reincidência do ato do próprio colega. Os profissionais que tiveram experiência em tratar pacientes suicidas sabem que, frequentemente, a reação imediata daqueles que cercam o paciente é serem cruéis e rejeitá-los. O profissional que é chamado para lidar com o paciente suicida, geralmente, encara uma crise particular que muito tem a ver com sua própria reação ao paciente, o de poder tomar a forma de rejeição.

Vinte anos depois, o quadro permanece problemático. Há ganhos no sentido de visibilidade da questão, mais pesquisas, porém, muito a ser desenvolvido para melhora no sentido de obter qualidade de vida durante a graduação. Vivenciar a realidade do ensino superior parece uma tarefa complicada para parte significativa dos alunos.

Brandtner e Bardagi (2010) explicitam que as revisões de literatura no contexto acadêmico, entre estudos nacionais e internacionais, realçam a existência de 15 a $29 \%$ de universitários com desenvolvimento de algum tipo de transtorno psiquiátrico durante a graduação. Assim, é necessário ir além da oferta da ajuda psicológica, é importante avaliá-las durante o curso, com foco em patologias como a ansiedade e a depressão, por serem os principais sofrimentos psíquicos quando se avaliam casos de alterações psicopatológicas.

Ainda conforme a fonte, em relação ao terceiro grau, há períodos mais intensos de mudança, como entrada na universidade e o período próximo à saída, que aparecem como ansiogênicos, interferindo negativamente na aprendizagem, por proporcionarem queda na atenção, concentração, redundando em baixo desenvolvimento de habilidades. Revisando estudo de Galindo, Moreno, Munõz e Conesa, pontua-se que ansiedade e depressão costumam manifestar-se dentro de um mesmo quadro de comorbidade, associando-se, geralmente, com abuso de substâncias, como álcool e drogas, o que torna ainda mais problemática a situação de discentes do Ensino Superior. Nesse sentido (2010, p. 84):

Avaliando especificamente alunos de Medicina, e utilizando o Inventário de Beck (BDI), Rezende, Abrão, Coelho e Passos (2008) encontraram prevalência de sintomas depressivos de $79 \%$, sendo $29 \%$ com grau leve, $31 \%$ moderado e $19,2 \%$ grave; neste estudo, os autores apontam uma correlação negativa entre sintomas de depressão, satisfação com o curso e atividades de lazer. 
Medeiros, Almeida e Ribeiro (2012), revisando estudos na área médica, também realçam a existência de um conjunto de situações estressantes que se desenvolvem no decorrer do curso de Medicina, desde o início da formação: mudanças metodológicas ocorridas antes do ensino superior até as primeiras desenvolvidas na universidade, o sentimento de desamparo do estudante com relação ao poder dos professores, as provas e exames com novas tonalidades, a presença de competição entre os próprios colegas, o encontro com o cadáver e as sensações que provocam, juntamente com o contato com a morte nos laboratórios de anatomia, a decepção com as primeiras notas, dentre outras situações.

Interessante o destaque dado por Chehuen Neto et al (2013) para os dados da literatura mundial de que estudantes universitários adotam estilos de vida não saudáveis que terminam por impactar diretamente a saúde mental. Os problemas estão mais intrinsecamente ligados ao consumo de bebida alcóolica, ao tabagismo, à prática de sexo inseguro, ao consumo de drogas ilícitas, à privação do sono, à falta de atividade física e maus hábitos alimentares. Os autores consideram precoce e elevado o consumo de drogas (lícitas e ilícitas), bem como a falta de qualidade alimentar.

$\mathrm{Na}$ pesquisa por eles conduzidas, foram significantes a associação do sexo masculino com o fumar, o início desse hábito durante o curso médico pelas meninas, o uso de drogas ilícitas por rapazes e, em ambos os sexos, piora da alimentação durante a graduação. Também são enfáticos ao afirmar que "vários estudos mundiais mostram que estudantes de medicina têm adotado um estilo de vida pouco saudável, apesar dos conhecimentos adquiridos durante a graduação". Os autores salientam, após estudar uma amostra de 324 estudantes, que, numericamente (2013, p. 45):

9\% dos acadêmicos já pensaram em suicídio; $96 \%$ já experimentaram bebida alcóolica; $25 \%$ já experimentaram droga ilícita, sendo $64 \%$ antes de ingressar na faculdade; $21 \%$ não usaram ou usaram raramente preservativo no último mês; $51 \%$ consideraram que sua alimentação piorou após ingresso na faculdade; $43 \%$ não realizaram qualquer atividade física no último mês.

Tais dados podem ser considerados alarmantes e mostram o quão premente se torna o desenvolvimento de medidas que melhorem o autocuidado e que também deem ao discente cuidado externo. Corroborando esse pensamento, Meleiro (2005) conta ser o período de formação médica longo e estressante, visualizado como um difícil modo de obter desenvolvimento e maturação. Marcado pelo isolamento social, os médicos em treinamento passam a maior parte de seu tempo inseridos em ambientes também médicos, o que acaba por cercear suas oportunidades de exposição a mentores maduros, tais como se espera socialmente. Isso acaba se tornando paradoxal, pois, segundo a autora (2005, p. 35-36): 
A maturidade é a qualidade pessoal singular mais importante em um excelente médico. Os pacientes geralmente preferem os médicos mais maduros, mais velhos. A maturidade é reconhecida por qualidades como humildade, autocontrole, autoconfiança, sabedoria, experiência e integridade. Essas qualidades tendem a aumentar com a idade da pessoa e com a aceitação da responsabilidade de adulto.

Conforme relatos de Millan e De Marco (1995), o problema de suicídio entre alunos da USP foi uma das razões pelas quais se criou o Grupo de Assistência Psicológica ao Aluno (GRAPAL). Após revisarem o número de suicídios entre os alunos de Medicina entre 1965 e 1985, chegaram a encontrar um quantitativo quadriplicado em relação à população em geral. Na Faculdade de Medicina da Universidade Federal do Amazonas, o Núcleo de Apoio Psicopedagógico e Psicossocial torna-se realidade também após tentativas de suicídio e suicídios consumados.

Já entre acadêmicos de medicina da Universidade Federal de Goiás, estudo conduzido por Amaral et al (2008) mostrou que, na população entrevistada, $26,8 \%$ apresentaram sintomas depressivos de acordo com escores do Inventário de Depressão de Beck. A prevalência de sintomas depressivos moderados e graves foi de 6,9\%. 19,9\% apresentaram sintomas leves. Em relação ao sexo, 33,5\% eram de mulheres e 19\% de homens. No tocante ao ano do curso, houve maior incidência entre alunos do terceiro e quarto anos. No inventário, tristeza, anedonia, baixa autoestima, perfeccionismo, irritabilidade, desinteresse por pessoas, redução da capacidade de trabalho e cansaço excessivo foram os itens mais pontuados. A prevalência de sintomas depressivos nesse estudo mostrou-se superior à média encontrada na população em geral, com indicação de que a escola médica possa ser fator predisponente para os sintomas.

Percebe-se, com Meleiro (2005), que a imaturidade pode comprometer a habilidade do jovem médico em cumprir com seu dever ante as necessidades dos pacientes, além de o efeito terminar por voltar-se contra si mesmo. A vulnerabilidade a danos pessoais reflete-se também no descontentamento profissional e as tarefas de médico ganham sentido de estresse para o profissional. Médicos que não amadurecem geralmente apresentam problemas emocionais não resolvidos desde a infância, enfrentando maior risco de deficiência profissional e crise de vida, frequentemente potencializados pelo estresse grande que permeia a prática.

Por isso, para Medeiros, Almeida e Ribeiro (2012), o alvo inicial da formação médica deveria ser o próprio estudante de Medicina. Para os autores, os discentes acabam por não saber claramente a razão de sua opção pelo curso, estando os alunos ingressantes tentando finalizar a tarefa básica da adolescência, representada pela aquisição de identidade pessoal e individuação enquanto pessoa.

Daí os autores proporem como pontos para uma discussão mais aprofundada: "lidar com cadáveres, a ética diante do aprendizado com cadáveres, a competição entre colegas e seus limites com a deslealdade, a medicina da 
pessoa ou aquela voltada para a população, campos de ação e limites da profissão médica" (MEDEIROS; ALMEIDA; RIBEIRO, 2012, p. 74).

Batista, Vilela e Batista (2015), por sua vez, corroboram os dados apontados pelos demais autores e, revisando estudos sobre o tema, também destacam como momentos de crise durante a formação: o ingresso no curso, o contato com o processo saúde-doença e seus determinantes sociais, o excesso de conteúdos a assimilar, o aprendizado das diversas habilidades e atitudes da profissão médica, a dificuldade financeira inerente a um processo longo de formação e, finalmente, a escolha da futura especialização, seguida de um processo de seleção para uma vaga em programa de residência médica.

Nesse diapasão, pode-se perceber que a entrada no curso e sua permanência nele tendem a ser problemáticas - e esses problemas comuns aparecem aqui pontuados por diferentes autores. É um primeiro desafio para o curso tornar suportável ao aluno sua vivência, sob pena de adoecimento ao longo do processo. A escola que pretende formar profissionais para cuidarem do maior bem humano - vida com saúde - não pode adoecer seus discentes.

Tais situações terminam potencializadas ao alinharem-se com interesses científicos e busca pela perfeição por parte dos discentes Tais interesses e perfeccionismo redundam em características como introversão, falta de presença social e de percepção, rigidez, um estilo de aprendizado passivo e interesse preferencial em procedimentos tecnológicos. Tais pontos tendem a impactar o exercício da Medicina, por esta exigir, aliada à competência técnica, habilidade social. De modo controverso, muitas habilidades interpessoais dos discentes acabam por serem desenvolvidas com residentes estressados e não maduros, e não com médicos socialmente competentes. Dessarte, o processo de formação médica e o treinamento ofertado resultam em baixa ajuda para alunos e residentes, os quais acabam por não possuírem habilidades adequadas (MELEIRO, 2005). De modo antitético, para Meleiro (2005, p. 59):

É um contrassenso sabermos que os estudantes de Medicina aprendem e trabalham nas consideradas melhores faculdades médicas do País, com as melhores equipes médicas e que, no entanto, essas equipes hospitalares em geral não se sensibilizam, negligenciando a saúde do estudante de Medicina, principalmente com referências pejorativas à doença mental. Os esforços das faculdades de Medicina nas últimas décadas em dar assistência psicológica ao aluno ainda ressoam pouco, devendo ser mais valorizados pelos próprios alunos e professores. Há uma resistência por parte dos próprios alunos em aceitar que precisam de ajuda psicológica e em procurá-la. Outras vezes, os professores desvalorizam, por comentários pejorativos, a importância do emocional dos pacientes; com isso, os alunos se fecham a qualquer abordagem nessa área.

Pensa-se que perceber a entrada no ensino superior como um período de transição na própria vida pode ser um ponto de partida para que o estudante entenda o processo pelo qual está passando. Batista, Vilela e Batista (2015), 
ilustrativamente, apontam pelo menos quatro âmbitos de transformação que ocorrem na vida do sujeito universitário, quais sejam: acadêmico, social, pessoal e vocacional/institucional. Refletindo sobre tais transformações, observam (2015, p. 326-327):

O âmbito acadêmico exige grande resiliência do aluno, demandando constantemente sua adaptação às estratégias de ensino-aprendizagem e aos novos ritmos com os quais se deparam nas diferentes etapas da graduação. A dimensão social da vida universitária requer posturas mais maduras nos diversos níveis de relações interpessoais estabelecidas pela atmosfera acadêmico-universitária. Em nível pessoal, a universidade demanda o fortalecimento da identidade, a partir de um maior conhecimento sobre si próprio e de uma construção pessoal mais ampliada sobre o mundo. Por fim, a dimensão vocacional/institucional destaca a importância do desenvolvimento de uma identidade vocacional, a partir do comprometimento com objetivos profissionais e/ou institucionais.

Os autores ainda salientam algumas situações de ensino-aprendizagem que podem resultar em sobrecarga psicológica. Nos primeiros anos do curso, o contato com a morte aparece como variável a ser pensada, já que a Anatomia pode ser vista como disparador da ansiedade. Já nos terceiros e quartos anos, quando se intensifica a relação com os pacientes e da interação com a equipe de cuidado, há vivência de sentimentos de impotência e insuficiência de conhecimentos e habilidades, além das dificuldades de conciliar necessidades pessoais e profissionais. Ao fim da graduação, nos quintos e sextos anos cursados pelo aluno em regime de internato, o acadêmico deve se dedicar à prática clínica, lidando diariamente com o sofrimento humano.

Tais atividades, conforme pontuado em estudos discutidos teoricamente, somam-se a outras exigidas pela graduação, como participação em atividades de monitoria, iniciação científica, extensão e estágios, o que dá mais peso à carga horária de estudos e dedicação ao curso, além das horas despendidas para estudo individual e trabalho em grupo (BATISTA; VILELA; BATISTA, 2015).

Concorda-se com os autores supra, para quem tais questões geram alto grau de responsabilidade da escola médica no processo, devendo a referida escola assumir integralmente os cuidados por um ensino humanizado e cuidar também dos discentes, já que o egresso reproduzirá, após formado, o tratamento recebido durante seus anos enquanto estudante, reproduzindo a lógica vivenciada na instituição.

Ao perceber uma demanda reprimida sob a lógica da saúde mental, Meleiro (2005) aponta algumas das possíveis consequências: o preconceito do futuro médico em face da Psiquiatria, a não-valorização do lado emocional do paciente pelo próprio médico, o não-reconhecimento dos transtornos mentais e da comorbidade psiquiátrica com quadros orgânicos. Para a autora (2005, p. 37): 
Há valores e normas do mundo da Medicina que moldam características singulares de médicos, seus valores, crenças, percepções e personalidades durante os anos de formação e treinamento para suas vidas profissionais. O indivíduo precisa estar disposto a comportar-se segundo essas normas e expectativas para passar pelas classificações e hierarquia da comunidade médica. Esse processo de socialização, segundo ele, resulta de comportamentos que são específicos de cada especialidade. Na maioria, os patologistas agem e comportam-se como outros patologistas, os pediatras agem e comportam-se como outros pediatras, e assim ocorre nas diversas especialidades. Os comportamentos de sucesso ou de fracasso, para atingir os objetivos pessoais individuais são reforçados por outros membros da comunidade médica.

Dessa forma, se profissionais formadores refletem preconceitos ligados ao campo da saúde mental, os estudantes tenderão a repeti-lo, conforme vão formando suas identidades médicas, incluindo nisso o processo formativo. Entende-se, assim, a importância do protagonismo estudantil, a qual pode ser estimulada por meio da assistência aos alunos. A necessidade de assisti-los é realçada por muitos estudiosos, em variados trabalhos no campo da pesquisa pela presença de psicopatologias encontradas em discentes, tanto para proporcionar o cuidado, quanto para desconstruir preconceitos ligados ao lado emocional e da citada saúde mental. Se o aluno encontra-se comprometido física e mentalmente, ajudando a perpetuar ciclos de ignorância no que toca à integralidade do ser, como pensar em protagonismo estudantil?

Nessa lógica, torna-se necessário que a escola médica assuma sua responsabilidade pelos alunos que forma, tenha compromisso com o ensino humanizado e em minimizar as múltiplas variáveis que podem funcionar como disparadoras de um processo formativo permeado pela doença. Isso necessariamente levará a um maior envolvimento estudantil, estimulando o protagonismo.

Obviamente, em uma produção científica como o escopo de um artigo, torna-se por demais abrangente tentar refletir todas as variáveis que podem ser fortalecedoras de um estudante com vez e voz. Por isso, optou-se por enfatizar um dos pontos que merece destaque para gestar discentes saudáveis e com condições de saúde para assumir o protagonismo: a formação de quem forma e "cuida" do estudante em sala de aula, o professor. É preciso transformar a praxe em práxis, ou seja, uma ação refletida sobre o próprio trabalho.

\section{A formação docente em perspectivas: a relação professor-aluno para além do paradigma médico}

No tocante à relação professor e aluno em seu imbricamento com a formação docente, no campo médico, a literatura aponta algumas lacunas e situações a serem repensadas. Para Costa, Cardoso e Costa (2012), no contexto 
universitário brasileiro, a carreira profissional docente seria um processo não acompanhado institucionalmente. A carreira docente apresenta-se sob duas diferentes perspectivas: a primeira tange o "status" profissional e fases da carreira acadêmica propriamente dita, a segunda versaria sobre os momentos pessoais pelos quais o professor passa até chegar a sua plenitude profissional. Assim, o desenvolvimento de uma carreira seria um processo e receberia influência de dois tipos de fatores: pessoais e institucionais.

Os autores, revisando estudos que analisaram as características de profissionais liberais que se tornaram professores-referência, destacaram quatro fatores que motivaram os alunos a perceber os docentes como referência: didática/metodologia de ensino, atitudes e qualidades pessoais do professor, domínio de conteúdo/conhecimento e interesse particular do aluno. Assim, pode-se concluir de que há a necessidade de desenvolver características cognitivas e não cognitivas para o desempenho da atividade docente.

Costa, Cardoso e Costa (2012) ainda destacam que, no Brasil, ainda não se conseguiu valorizar a formação pedagógica dos professores médicos. Um estudo da Associação Brasileira de Educação Médica, realizado pela Comissão de Avaliação das Escolas Médicas com 28 escolas de Medicina, verificou que estes cursos, de modo geral, não oferecem formação pedagógica ao corpo docente.

Assim, fica em segundo plano uma formação reflexiva do professor, o que envolveria pensar na ação e sobre a ação. Para que um professor seja percebido como competente em sua atividade, é considerada ideal a capacidade de criar um ambiente agradável para o ensino, o que, certamente, levaria a implicar o aluno no processo e o retorno fornecido pelo discente acerca do processo educativo (COSTA; CARDOSO; COSTA, 2012).

Daí os autores salientarem que, para enquadrar um novo modelo de ensino, o professor precisa modificar sua dinâmica de atuação e sua convivência com os estudantes. A compreensão da importância de desenvolver características que levem o aluno a uma aprendizagem significativa é fundamental para o professor e também para as instituições, que devem se basear nestas características no momento de formarem seu corpo docente. Entende-se que é nesse campo de formação que conceitos como o de "protagonismo estudantil" podem ser inseridos, no intuito de ressignificar paradigmas pedagogicamente enraizados na cultura acadêmica.

Refletindo sobre a prática pedagógica no campo médico, há mais de 20 anos Ramos-Cerqueira (1997) já destacava que a história da medicina, da prática médica e do ensino médico foi marcada por diferentes concepções de seu objeto, que podem ser agrupadas em duas grandes vertentes: na primeira, compreender-se-ia que a doença tem um sentido, além de uma causa, para a pessoa que sofre, e estaria inserida na trama de uma história de vida, de afetos, de interrelações. Na segunda, a compreensão da doença seria de uma inscrição num corpo e que deveria ser tratada dentro do campo da racionalidade médica, o que significa transformá-la em um objeto de estudo que seguiria o método das ciências naturais, o pensamento mecanicista, dentro de um circuito anátomo-patológico. 
Para a autora, o segundo modelo prevaleceu, recebendo críticas por sua consciência "fatiada". Mesmo após todos esse lapso temporal, no campo do ensino, ainda se tem uma relação professor-aluno em que inexiste espaço para a subjetividade, para o afeto, para o desejo, sendo este um aspecto generalizado, conforme citação abaixo transcrita (p. 188):

Observa-se isto em todas as modalidades de relação professor-aluno, mas este fato parece ser mais nítido na escola médica, na qual o modelo autocrático e hierárquico predomina do ciclo básico à pós-graduação. É evidente, na relação professor-aluno, a relação entre desiguais, em que ter o saber, ter o conhecimento, empresta poder a quem o tem e desqualifica aquele que não o possui, levando a um estilo de aprender em que a passividade e a atitude crítica são as marcas.

Xavier (2014) chama a atenção para as abordagens sobre as condições de trabalho e a saúde dos professores, afirmando que, conforme os teóricos da chamada "proletarização", a lógica racionalizadora do capital impõe a rotinização do trabalho, o excesso de especialização e hierarquização, o que contribui para a desqualificação (separação entre concepção e execução do trabalho) e falta de autonomia (perda de controle e de poder decisório sobre o próprio trabalho) dos professores. Vale ressaltar que, no contexto médico, é rotineira a acumulação do trabalho (muitas vezes com vários empregos), o que nos leva a questionar que papel tem o ensino na vida do profissional.

Se as demandas citadas pela autora nos alertam para que, em um ambiente específico de trabalho, a demanda causa sobrecarga física e psíquica, estariam os professores revivendo seu próprio processo formativo? Estaríamos entrando em um ciclo que precisa ser visto e percebido, para, enfim, poder ser alterado, perspectivando o estudante sob outro viés?

Afinal, na perspectiva de Ramos-Cerqueira (1997), no ensino geral e, no ensino médico em especial, existe a "suposição" de que o vínculo de dependência seria "natural" e se manifestaria em algumas formas de pensar e agir como as de que o professor sabe mais que o aluno, devendo, portanto, protegê-lo para que este não cometa erros, que o professor deve e pode julgar o aluno, determinando a legitimidade de seus interesses.

Assim, chegamos a um outro ponto de partida no processo de formação, agora do docente: a reflexão de que "ainda que conscientemente o professor defina como meta desenvolver a reflexão crítica, a aprendizagem criativa, o ensino ativo, a promoção da individualidade do aluno, nada se dará se o vínculo pedagógico for um vínculo de submissão" (RAMOS-CERQUEIRA, 1997, pp. 189-190).

Veras e Ferreira (2010) salientam que a tradicional valorização da dimensão cognitiva em detrimento da afetiva, na trajetória do pensamento e do conhecimento humano, e a visão dualista do homem enquanto corpo/mente, matéria/ 
espírito, afeto/cognição, têm dificultado a compreensão das relações entre ensino e aprendizagem e da própria totalidade do ser, limitando o processo de formação de estudantes de vários níveis de escolaridade.

Respaldando-se na teoria de Wallon, as autoras, com foco em uma leitura histórico-cultural, notam que a dimensão afetiva, ao longo de todo o desenvolvimento do indivíduo, tem um papel fundamental para a construção da pessoa e do conhecimento. Essa afetividade representaria um conjunto funcional abrangente, incluindo sentimentos, emoção e paixão, dimensões que necessitariam estar presentes na prática educativa, levando-a para além de uma dimensão estritamente técnica.

Outro argumento para uma mudança do modelo tradicional no ensino médico foi a aprovação das Diretrizes Curriculares Nacionais do Curso de Graduação em Medicina, conforme Perin et al (2009) destacam. Houve uma mudança paradigmática do processo de educação superior, de um modelo biomédico para outro orientado pela saúdedoença nos diferentes níveis de atenção, na perspectiva da integralidade da assistência, de uma dimensão individual para uma dimensão coletiva; de currículos rígidos para currículos flexíveis, os quais exigem modernas tecnologias da aprendizagem, habilidades e atitudes, além de múltiplos cenários de estudo.

Depois de todo o exposto, tem-se certeza de que é necessário refletir sobre a relação do professor com o aluno e como isso tende a reformular a formação inicial e continuada do docente, gerando retornos para o aluno. Afinal, conforme estudo conduzido por Rios e Schraiber (2012), a atuação de professores que se colocam no lugar de quem detém o saber e o poder como instrumentos de submissão do outro, seja aluno ou paciente, cria um ambiente de tensão, desqualificação e redução do outro a condição de objeto que beira a violência. É preciso pensar além da necessidade do protagonismo, é preciso pensar o resultado da ausência dele.

Para as autoras, nesse âmbito, observa-se que o pouco protagonismo dos alunos se dá por temor à humilhação decorrente das dúvidas ou dos erros, gerando o que denominam por "pedagogia do medo", a qual provoca inquietação, revolta e sofrimento. Apesar dessas características, a citada "pedagogia do medo" mostra-se legitimada institucionalmente. $\mathrm{O}$ resultado desse aprendizado apareceria na atitude de certos alunos que, em situação semelhante a dos professores, comportam-se como agentes de violência contra colegas e mesmo contra professores menos autoritários.

Lembra-se aqui das palavras de Freire (1995), para quem formar é muito mais do que simplesmente treinar, não sendo transferir conhecimento, mas sim criar possibilidades para sua construção. Para ele, é somente pensando criticamente a prática do passado ou do presente que se pode melhorar a próxima prática. O diálogo, na perspectiva freiriana, ultrapassa um encontro das pessoas, pois que não se esgota na relação eu-tu: pronunciar as palavras é um ato de pronúncia do mundo e sua consequente transformação, isso se tornaria uma exigência existencial, pois o ensinar não pode se reduzir a um ato de depositar ideias de um sujeito no outro. 
Finaliza-se a discussão com uma citação pertinente, também de Paulo Freire (1996, p. 25):

O professor que não leva a sério a sua formação, que não estude, que não se esforce para estar à altura de sua tarefa não tem força moral para coordenar as atividades de sua classe. Isto não significa, porém, que a opção e a prática democrática do professor ou da professora sejam determinadas por sua competência científica. Há professores e professoras cientificamente preparados mas autoritários a toda prova. O que quero dizer é que a incompetência profissional desqualifica a autoridade do professor.

Ratificar o pensamento freiriano é entender a relação professor e aluno para além de um mero formalismo, é entender que o discente precisa ter vez e voz para "(re)xistir" em sala de aula. É pensar o protagonismo estudantil como condição fundante do ensino e não como uma prática "da moda" ou como acessório de uma educação com qualidade.

\section{Considerações finais}

O artigo procurou tratar da docência no campo médico enquanto um desafio para a formação, levantando reflexões em torno de perspectivas. O objetivo foi discutir alguns dos desafios apontados pela literatura, privilegiando o protagonismo estudantil.

De modo geral, os resultados mostraram que a formação inicial e continuada de professores na área é urgente, principalmente quando se considera sua ausência, a falta de percepção do aluno como sujeito da aprendizagem e silenciamentos de questões que potencializam a evasão escolar discente, como excesso de cobrança e pouco protagonismo estudantil.

Isso levou a perceber, como principal conclusão, que o campo incipiente da formação de professores necessita ser problematizado: o professor-médico precisa se perceber mais professor, o que o levará a pensar o campo pedagógico, e menos médico, para relativizar paradigmas de sua própria formação e enxergar o aluno em uma perspectiva biopsicossocial, mais como sujeito e menos como paciente.

A presença do protagonismo não foi praticamente percebida e levantou uma questão interessante: quais seriam os resultados de sua ausência? Pelos dados aqui levantados, entende-se que tendem a ser negativos, mas, como esse não foi o nosso foco, pensa-se ser essa uma limitação do estudo, elencando-se como sugestão a necessidade de pesquisas nesse viés, inclusive, também outras nos moldes da revisão bibliográfica. 


\section{Referências}

AMARAL, G. F. et al. Sintomas depressivos em acadêmicos de medicina da Universidade Federal de Goiás: um estudo de prevalência. Rev. psiquiatr. Rio Gd. Sul, Porto Alegre, v. 30, n. 2, p. 124-130, ago. 2008. Disponível em: <http://www.scielo.br/scielo.php?script=sci arttext\&pid=S0101-81082008000300008\&lng=en\&nrm=iso $>$. Acesso em: 12 jul. 2018.

ARRUDA, P. V. Conceito de medicina psicossomática. In: Gastroenterologia Clínica. São Paulo: Manode, 1990, p. 11-38.

BATISTA, N.A., VILELA, R.Q.B., BATISTA, S.H.S.S. Educação Médica no Brasil. São Paulo: Cortez, 2015. 398p.

BELLODI, P.L. Tutoria: mentoring na formação médica. São Paulo: Casa do Psicólogo, 2005.

BRANDTNER, M.; BARDAGI, M.. Sintomatologia de depressão e ansiedade em estudantes de uma universidade privada do Rio Grande do Sul. Gerais, Rev. Interinst. Psicol. [online], v. 2, n. 2, p. 81-91, 2010. ISSN 1983-8220.

CHEHUEN NETO et al. Estudantes de Medicina sabem cuidar da própria saúde? HU Revista, v. 39, n. 1-2, p. 45-53, jan-jun, 2013. Disponível em: <https://hurevista.ufjf.emnuvens.com.br/hurevista/article/view/1931>. Acesso em: 01 jul. 2018.

COSTA, N. M. da S. C.; CARDoso, C. G. L. V.; COSTA, D. C.. Concepções sobre o bom professor de Medicina. Revista Brasileira de Educação Médica, Rio de Janeiro, 36(4):499-505; 2012. Disponível em: <http://www.scielo.br/scielo.php?script=sci_ arttext\&pid=S0100-55022012000600008\&lng=pt\&nrm=iso>. Acesso em: 01 jul. 2018.

FREIRE, P. À sombra desta mangueira. São Paulo: Olho D’àgua, 1995.

FREIRE, P. Pedagogia da Autonomia:saberes necessários à prática educativa. 33ed. São Paulo: Paz e Terra, 1996.

MEDEIROS, J. G. M.; ALMEIDA, J. C.; RIBEIRO, P. C. A relação estudante-paciente. In: BRASIL, M. A. A. et al. (Ed.). Psicologia médica: a dimensão psicossocial da prática médica. Rio de Janeiro: Guanabara Koogan, 2012. p. $72-78$.

MELEIRO, A. M. A. A. S. O médico como paciente. São Paulo: Lemos-editorial, 2005.

Meleiro, A. M. A. A. S. Suicídio entre médicos e estudantes de medicina. Rev. Assoc. Med. Bras., São Paulo, v. 44, n. 2, p. 135-140, jun. 1998. Disponível em: <http://www.scielo.br/scielo.php?script=sci_arttext\&pid=S0104-42301998000200012\&lng=e n\&nrm=iso $>$. Acesso em: 12 jul. 2018.

MILLAN, L. R., DE MARCO, O. L. N. A procura espontânea de assistência psicológica pelo estudante de medicina. Rev ABP-APAL, v. 17, n. 1 , p. $11-6,1995$.

MILLAN, L.R. et al. O universo psicológico do futuro médico: vocação, vicissitudes e perspectivas. São Paulo: Casa do Psicólogo, 1999.

PERIM, G. L. et al. Desenvolvimento docente e a formação de médicos. Rev. bras. educ. med. [online], v. 33, suppl. 1, p. 70-82, 2009. ISSN 0100-5502. Disponível em: <http://dx.doi.org/10.1590/S0100-55022009000500008>. Acesso em: 02 jul. 2018.

RAMOS-CERQUEIRA, A. T. A.. A prática pedagógica como processo de comunicação - a relação professor-aluno como eixo: o ponto de vista psicológico. Interface (Botucatu) [online], v. 1, n. 1, p. 187-192, 1997. ISSN 1807-5762. Disponível em: <http://dx.doi. org/10.1590/S1414-32831997000200015>. Acesso em: 12 jul. 2018. 
RIOS, I. C.; SCHRAIBER, L. B. A relação professor-aluno em medicina - um estudo sobre o encontro pedagógico. Rev. bras. educ. med. [online], v. 36, n. 3, p.308-316, 2012. ISSN 0100-5502. Disponível em: <http://dx.doi.org/10.1590/S0100-55022012000500004>. Acesso em: 12 jul. 2018.

VERAS, R. S.; FERREIRA, S. P. A. A afetividade na relação professor-aluno e suas implicações na aprendizagem, em contexto niversitário. Educ. rev. [online], n. 38, p. 219-235. 2010. ISSN 0104-4060. Disponível em: <http://dx.doi.org/10.1590/S0104$40602010000300015>$. Acesso em: 12 jul. 2018.

VOSGERAU, D. S. R.; ROMANOWSKI, J. P. Estudos de revisão: implicações conceituais e metodológicas. Rev. Diálogo Educ., Curitiba, v. 14, n. 41, p. 165-189, jan./abr. 2014. Disponível em: <https://periodicos.pucpr.br/index.php/dialogoeducacional/article/ view/2317/2233>. Acesso em: 4 fev. 2018.

XAVIER, L. N. A construção social e histórica da profissão docente: uma síntese necessária. Revista Brasileira de Educação, v. 19, n. 59, p. 827-849, out.-dez. 2014. Disponível em: <http://www.scielo.br/scielo.php?script=sci_arttext\&pid=S1413-24782014000900002\& lng=pt\&nrm=iso\&tlng=pt $>$. Acesso em: 10 jul. 2018.

Recebido em: julho/2018

Aceito em: outubro/2018

\section{Endereço para correspondência:}

Adan Renê Pereira da Silva <adansilva.1@hotmail.com>

Av. General Rodrigo Octávio, 6200 - Coroado I

69080-900, Manaus, AM, Brasil 